\title{
A CASE OF KLIPPEL TRENAUNAY SYNDROME
}

Pagadpally Srinivas ${ }^{1}$

1Associate Professor, Department of Paediatrics, Vinayaka Missions Medical College and Hospital, Karaikal.

\section{ABSTRACT}

\section{BACKGROUND}

Klippel-Trenaunay syndrome is a rare congenital anomaly involving the skin and the vascular compartment. It consists of cutaneous vascular malformations (Port-wine stain), bony and soft tissue hypertrophy and varicose veins. We report the case of a 12-year-old boy with this syndrome.

\section{KEYWORDS}

Klippel-Trenaunay, Cutaneous, Port-Wine Stain, Vascular Malformations.

HOW TO CITE THIS ARTICLE: Srinivas P. A case of Klippel Trenaunay syndrome. J. Evolution Med. Dent. Sci. 2016;5(25):1346-1348 DOI: $10.14260 /$ jemds/2016/317

\section{INTRODUCTION}

Klippel-Trenaunay syndrome is a rare cutaneous-vascular anomaly. It is a progressive syndrome-child can be born with only a port wine stain. The other anomalies-varicosities and bony/soft tissue hypertrophy can gradually progress. Bony/soft tissue hypertrophy usually involve only one limb.

\section{CASE HISTORY}

A 12-year-old male child was brought to the OPD with complaints of swelling of the arms and leg since birth. On examination there was uniform hypertrophy of the right side of the body, hypertrophy of the soft tissues of the right side with overgrowth of right leg and foot and fingers of both upper limbs, hyperpigmented verrucous plaque lesions noticed over the right axilla and right side of neck. Dilated engorged veins were noted over the lower limbs bilaterally.

There was scoliosis, haemangioma was noted over the palmar surface of right hand. Hemihypertrophy of right index and middle fingers and left index finger. Left lower limb hemihypertrophy, secondary varicose veins over lateral aspect of the foot, right leg and thigh, syndactyly. Sephanofermoral junction veins were found to be incompetent. Neurocutaneous marker was noted. Resolved cellulitis due to? lymphoedema was noted over the lower limbs.

On taking birth history, it came to light that the child had increased thickness of right lower limb including left foot and right hand. He developed reddish lesions on the body, which resolved on its own (Port wine stain). Then the child developed progressive increase in girth of upper and lower limbs on the right side. Based on the history and clinical findings, a clinical diagnosis of Klippel Trenaunay syndrome was made. Dermatology and orthopaedic opinion was sought, which confirmed the diagnosis. Ophthal examination was normal.

\section{Gen Exam}

\begin{tabular}{|c|c|c|}
\hline Circumference & Right & Left \\
\hline Forearm & 12 & 14 \\
\hline Mid-thigh & 21 & 19 \\
\hline Calf & 17 & 15 \\
\hline
\end{tabular}

Financial or Other, Competing Interest: None.

Submission 08-02-2016, Peer Review 06-03-2016,

Acceptance 14-03-2016, Published 28-03-2016.

Corresponding Author:

Dr. Pagadpally Srinivas,

27, Vellai Pillayar Koil Street,

(Near Shakti Medam), Kottucherry,

Karaikal-609609, Pondicherry State.

E-mail: sreenu77@gmail.com

DOI: $10.14260 /$ jemds $/ 2016 / 317$

\section{Investigation}

CBC, Peripheral smear- Microcytic Anaemia.

X-ray lower limbs- Soft tissue and bony hypertrophy.

Spine LS: AP/LAT-Scoliosis.

USG abdomen- Normal.

MRI Brain- Normal.

MRI Leg below knee- Uniform hypertrophy.

MRI abdomen- Normal.

Doppler study of arteries of lower limb vessels- Normal.

\section{DISCUSSION}

Klippel-Trenaunay Syndrome was first described by two French doctors, Klippel and Trenaunay in $1900 .{ }^{1}$ KlippelTrenaunay Syndrome (KTS) is characterized by a triad of portwine stain, varicose veins and bony and soft tissue hypertrophy. It generally affects only one extremity. ${ }^{2}$ Lesions are present at birth and in approximately $75 \%$ of patients they appear before 10 years of age. ${ }^{3}$ The difference between KTS and Klippel-Trenaunay-Weber Syndrome (KTWS) is that the latter includes significant arteriovenous malformations in the affected extremity. 4

Haemangiomas are often apparent at birth or by second week of age. 5 Port-wine stain or flat haemangioma is a vascular malformation present at birth and that does not show tendency toward involution. It is often unilateral and segmented, never crossing the midline. It increases in proportion to the child's growth and may involve any part of the body, although face and cervical region are the most commonly affected areas. Lesions may be light pink in infancy and become progressively darker (Dark Red) as the child ages. ${ }^{6}$ Haemangiomas may be limited or extend to deeper areas of skin including bones, muscles and organs, worsening the prognosis of the disease.

Varicose veins observed in patients with the syndrome may be noticed in early infancy, but they generally become prominent in a later stage and progress until adolescence. They are a large and lateral vein, which starts on the foot or leg proximally and extends until the buttocks or gluteus region. These areas may remain stable or enlarge gradually causing pain, lymphedema, thrombophlebitis and ulcers.

Hypertrophy is the third symptom to appear in the syndrome and it can be secondary to length increase (Bone involvement) and/or circumference increase (Soft Tissue Involvement). It can be observed at birth and progresses during the first years of life. In adolescence when the child's growth cycle period has finished, the limb will stop growing. Bone and soft tissue hypertrophy is a result of increased 
growth. In many cases, limb length is affected. In most cases the girth of the limb is larger, although atrophy is seen in some patients. The lower limb is involved in about $95 \%$ of patients, while upper limb involvement is seen in $5 \% .{ }^{7}$ rarely only the trunk is involved.

It affects males more than females. When KlippelTrenaunay Syndrome is associated with arteriovenous fistula, it is known as Klippel-Trenaunay-Weber Syndrome. Although the cause of KTS is still unknown, it is hypothesized that it is caused by a mesodermal abnormality during foetal development leading to vascular and soft tissue malformations in the affected limb. ${ }^{8}$ McGrory and Amadio. ${ }^{9}$ believed that an underlying mixed mesodermal and ectodermal dysplasia was responsible for development of KTWS. Klippel-Trenaunay Syndrome might develop due to a single gene defect (Happle, 1993). ${ }^{10}$ rarely it can be inherited as an autosomal dominant trait.11

There is no cure for this disorder. Therapeutic objectives seek to improve the patient's condition and treat the consequences of severe lesions and length discrepancy. Treatment of port-wine stains is done with pulsed dye laser therapy. It is best to start treatment early because younger children require fewer sessions and show more favourable results. Treatment yields better results when applied to lesions in the face and trunk as compared to extremities.

Nevertheless, it only contributes to the superficial treatment of haemangiomas. When varicose veins are present, compression stockings are recommended for venous insufficiency. Surgical treatment is only recommended in symptomatic cases of superficial varicose veins. The use of orthopaedic braces is a good option to prevent the development of vertebral deformities in case of hypertrophy of the lower limbs. With time corrective bone surgery may be necessary to treat significant limb length discrepancy.

In conclusion, patients diagnosed with KTS must be evaluated once a year or more frequently based on clinical recommendation in order to keep the disease under control. If the disorder progresses, examination should be done and surgical intervention should be considered for the correction of lower limb length discrepancy. Research in genetics should be encouraged, so that in the future we may be able to understand the aetiology of this disease.

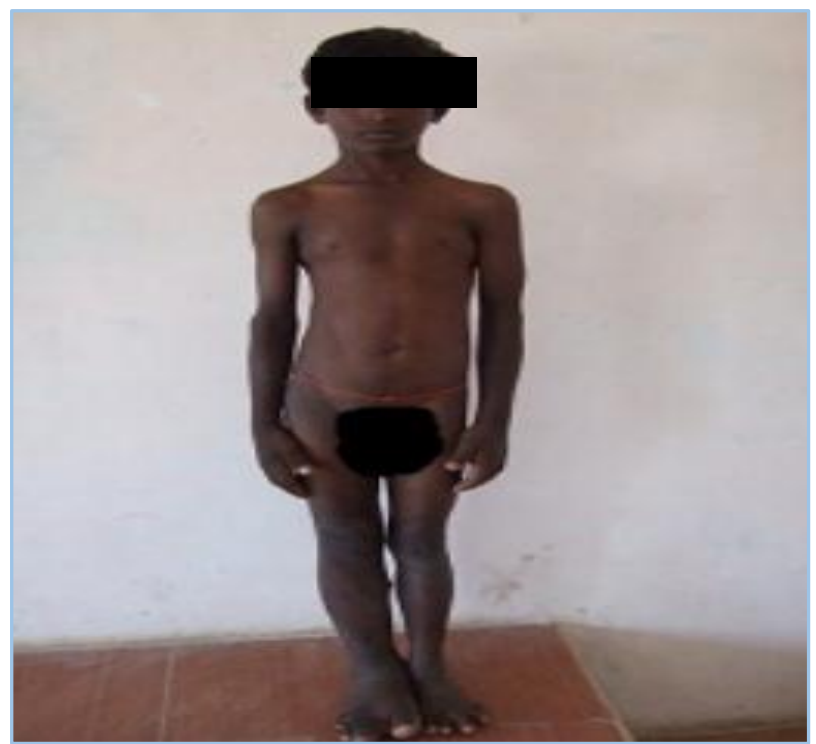

Fig. 1: Child with KTS

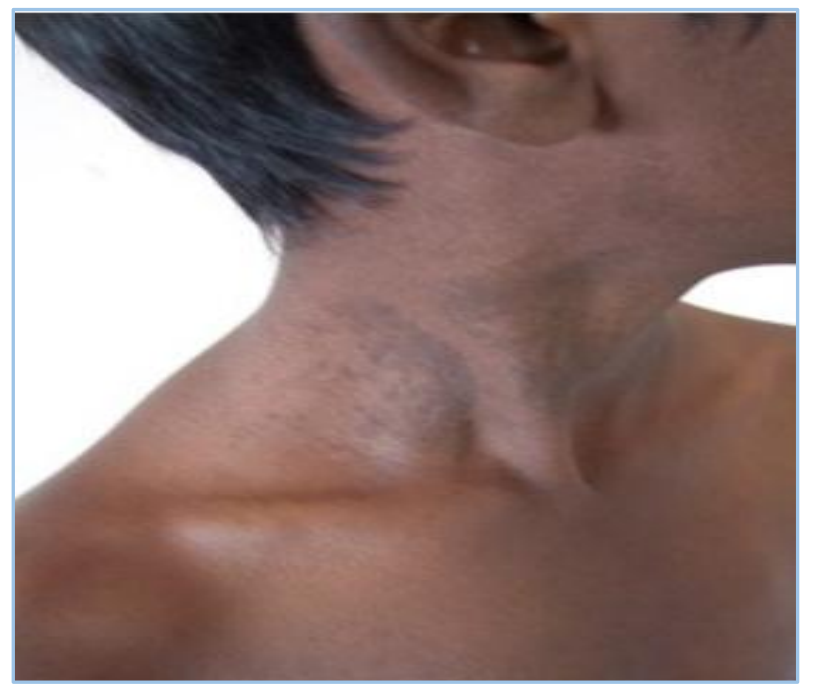

Fig. 2: Port Wine Stain

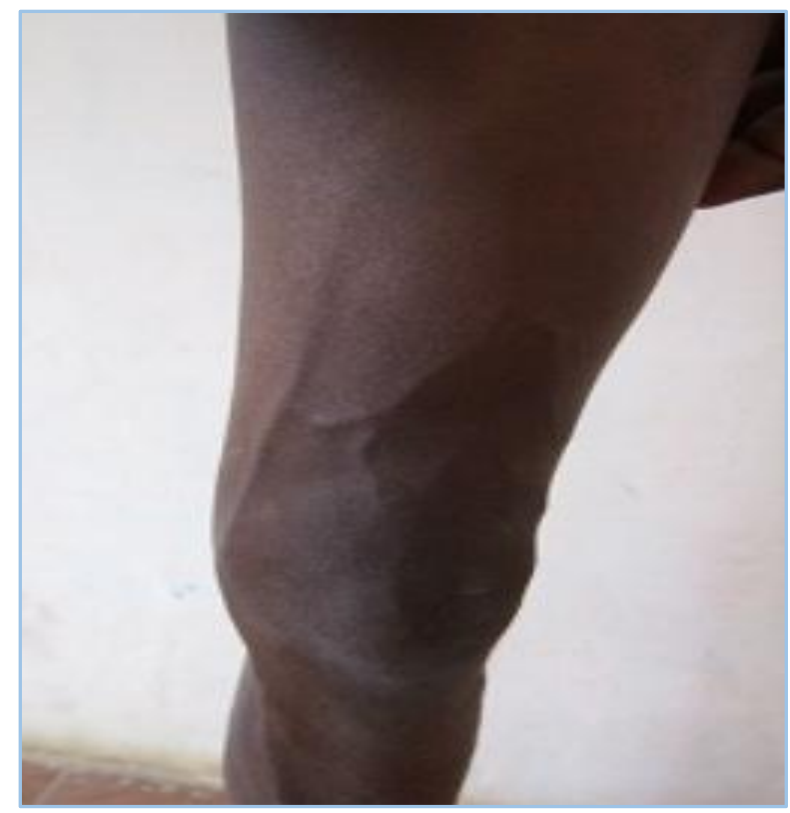

Fig. 3: Varicose Vein

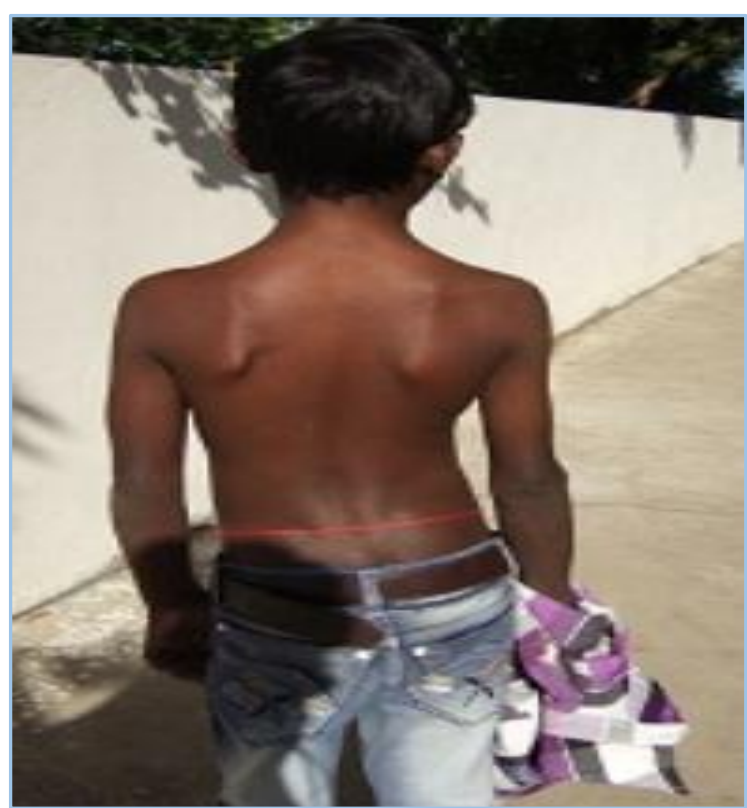

Fig. 4: Scoliosis 


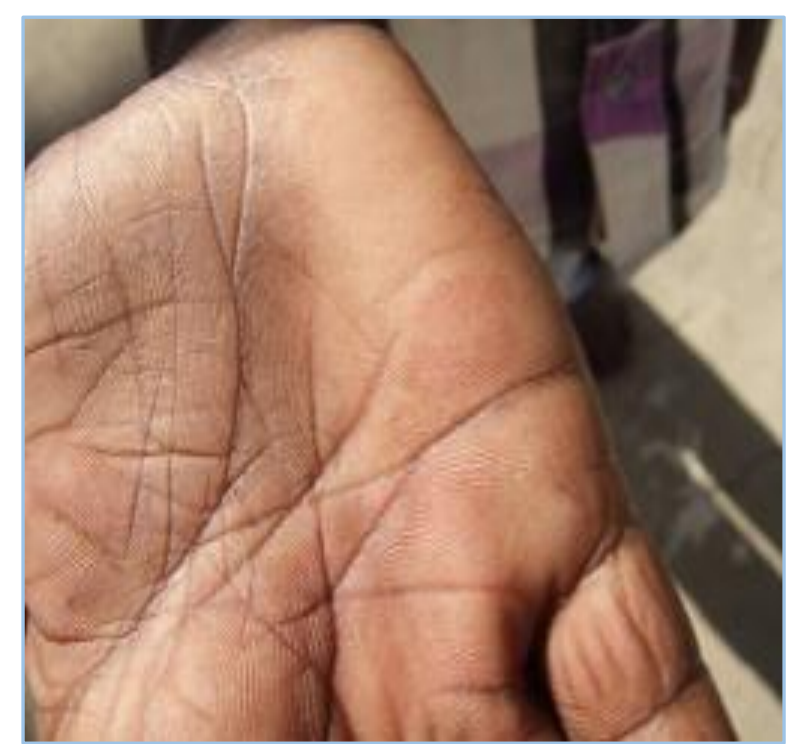

Fig. 5: Haemangioma

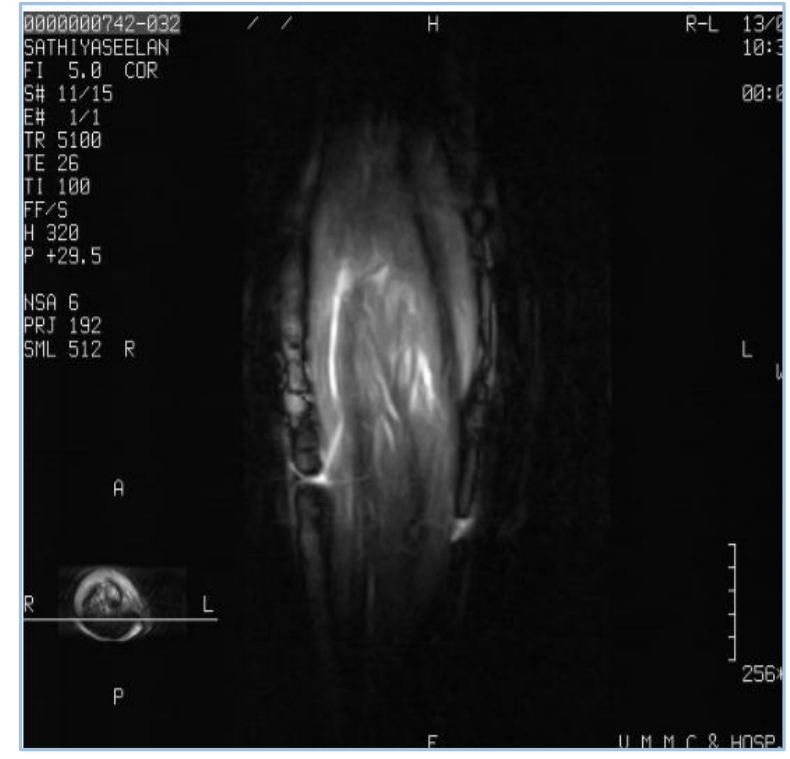

Fig. 6: MRI L LEG-Uniform Hypertrophy

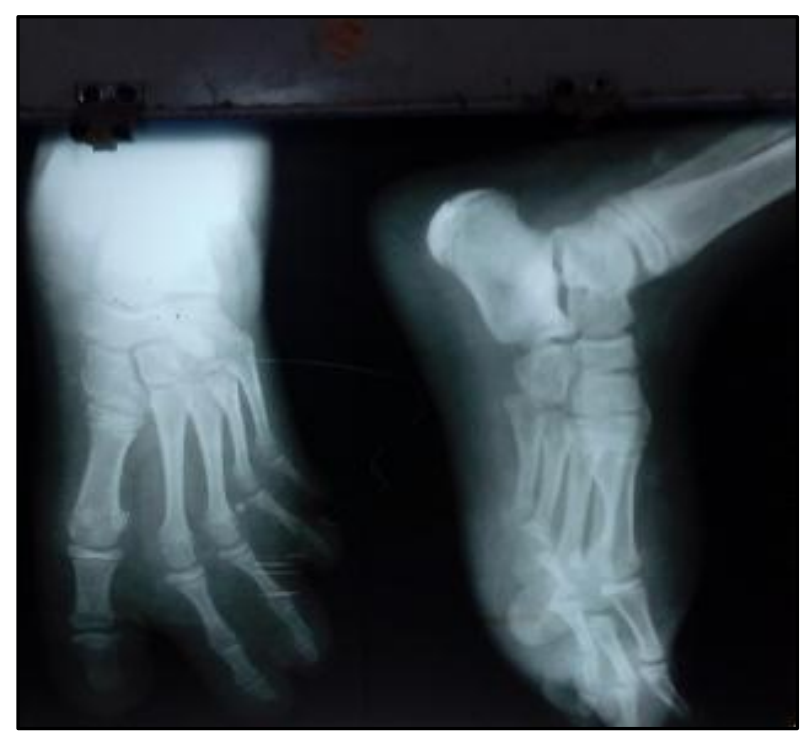

Fig. 7: X Ray-Soft Tissue \& Bony Hypertrophy

\section{REFERENCES}

1. Klippel $M$, Trenaunay $P$. Du naevus variqueux osteohypertrophique. Archives Generales de Medicine 1900;185:641-672.

2. Lane A, Darmstadt GL. Distúrbios vasculares. In: Behrman RE, Kliegman RM, Arvin AM, et al. Tratado de Pediatria. Rio de Janeiro: Editora Guanabara Koogan; 1997;2128-32.

3. Favorito LA. Vesical hemangioma in patient with klippeltrenaunay-weber syndrome. J Urol 2003;29(2):149-50.

4. Tonsgard JH, Fasullo M, Windle ML, et al. Klippeltrenaunay-weber syndrome. Paediatrics: General Medicine Articles 2006.

5. Samuel M, Spitz L. Klippel-trenaunay syndrome: clinical features, complications and management in children. British Journal of Surgery 1995;82(6):757-761.

6. Gontijo B, Pereira LB, Silva CMR. Malformações vasculares. An Bras Dermatol 2004;79(1):7-25.

7. Phadke SR. Klippel trenaunay syndrome. Atlas of Genetics and Cytogenetics in Oncology and Haematology 2009;13(2):153-155.

8. Baskerville PA, Ackroyd JS, Browse NL. The aetiology of the klippel-trenaunay syndrome. Annals of Surgery 1985;202(5):624-627.

9. McGrory BJ, Amadio PC. Klippel-trenaunay syndrome: orthopaedic considerations. Orthopedic Review 1993;22(1):41-50.

10. Happle R. Klippel-trenaunay syndrome: is it a paradominant trait? British Journal of Dermatology 1993;128(4):465-6.

11. Ceballos-Quintal JM, Pinto-Escalante D, Castillo-Zapata I. A new case of klippel-trenaunay-weber (KTW) syndrome: evidence of autosomal dominant inheritance. American Journal of Medical Genetics 1996;63(3):426-427. 